NOTE

\title{
Inspiration by Magellanic penguins: reduced swimming effort when under pressure
}

\author{
Rory P. Wilson*, Ilka Zimmer \\ Leibniz Institut für Meereswissenschaffen, Düsternbrooker Weg 20, 24105 Kiel, Germany
}

\begin{abstract}
Some marine mammals may increase their underwater locomotor efficiency by taking down little air for dives and descending passively, although at the point of maximum depth they presumably have to use energy to counteract the downthrust, to stop themselves sinking further. Birds, having considerable quantities of body-associated air, would appear not to have this option. However, measurements of locomotor activity and inspiratory behaviour of free-living, diving penguins has revealed that birds regulated the inspired air volume so that upthrust, primarily derived from depth-related changes in air volume, was minimal and constant at the preferred foraging depth. Although this results in minimized costs of travel, it means total body oxygen stores have to vary with depth, something that helps explain why dive duration is so closely correlated with depth in birds.
\end{abstract}

KEY WORDS: Buoyancy $\cdot$ Penguins $\cdot$ Air-breathing $\cdot$ Locomotor costs

\section{INTRODUCTION}

Swimming is costly for marine endotherms (SchmidtNielsen 1972, Williams 1999) and comprises a substantial fraction of their overall energetic budget (Costa \& Gales 2003). Yet high swimming costs mean that available body oxygen stores are used rapidly, which reduces the time the animals can spend underwater, and therefore compromises their utilisation of the water column. Considerable selection pressure on reduced costs of locomotion is thus expected. In keeping with this, various energy-saving strategies in animal behaviour have been demonstrated including optimum travel speeds (Thompson et al. 1993), burst and glide swimming (Crocker et al. 2001), porpoising (Au \& Weihs 1980, cf. Yoda et al. 1999), wave riding (Williams et al. 1992) and extended, passive descents during diving in some marine mammals, particularly pinnipeds (Williams et al. 2000, Sato et al. 2003). This latter option stems from animals expiring before diving, so that high body densities and diminishing residual lung volumes with increasing depth lead to animals being able to sink without engaging in muscular locomotor activity (Skrovan et al. 1999, Williams et al. 2000). This option is not open to diving birds, however, which have considerable amounts of air trapped in the feathers for insulation (Wilson et al. 1992) and, in any event, inspire before dives (Kooyman 1989). Despite reduced buoyancy with increasing depth due to air compression effects, air volumes are so high that most of these animals are not expected to achieve negative buoyancy at depths which might be realistically used for foraging (Wilson et al. 1992).

The present study monitored the inspiratory and locomotor behavior of a free-living, highly-specialised diving bird, the Magellanic penguin Spheniscus magellanicus, to examine the effort involved in swimming as a function of depth-modulated upthrust. It could thereby be determined whether diving birds might have specific behavioural traits helping them to minimize energy expenditure, despite being constrained by such large volumes of air associated with the body. 


\section{MATERIALS AND METHODS}

A total of 15 Magellanic penguins breeding at Cabo Virgenes and Peninsula Valdes, Argentina, were equipped with various loggers; 5 with units to determine swim speed and depth (Wilson et al. 2002a), 5 with units to determine flipper beat frequency and amplitude as a function of depth (Wilson \& Liebsch 2003) and a further 5 to determine beak angle during breathing at the surface between dives (Wilson et al. 2002b) because beak angle can be used as a proxy for

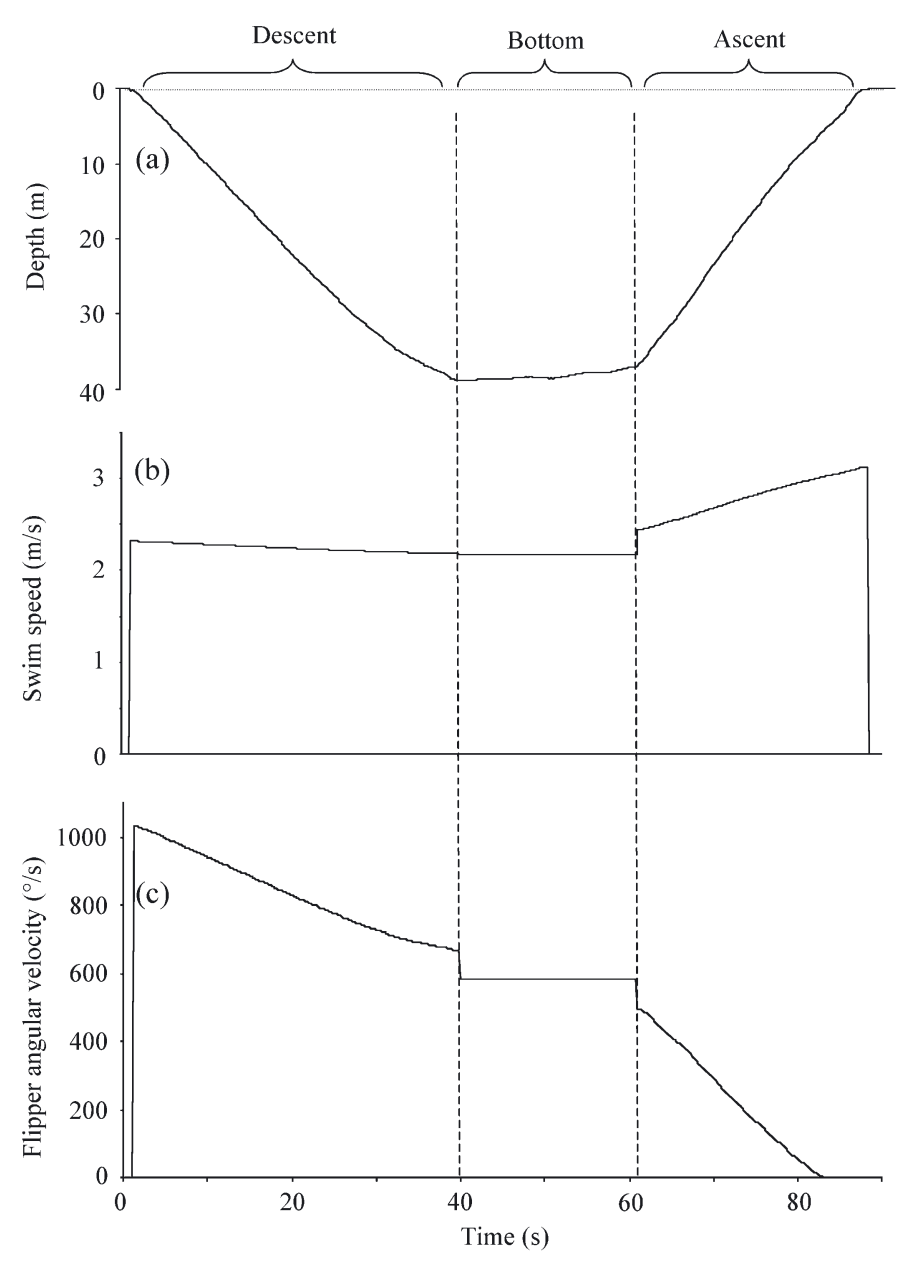

Fig. 1. Spheniscus magellanicus. Changes in dive parameters over the course of a typical, Magellanic penguin U-shaped dive: (a) depth profile, (b) swim speed, (c) flipper angular velocity. Depth data are taken from a single dive, but swim speed and flipper angular velocity data are from the presented depth data and means of regressions of swim speed versus depth and flipper angular velocity versus depth from a total of 10 birds (5 per parameter). This was undertaken separately for descent, bottom and ascent phases, which is why there is an occasional apparent step in values over time for transitions between the various phases. Flipper angular velocity values of 0 while the bird was in the water column indicate passive gliding to the surface inhaled air volume (Wilson et al. 2003). Attachment procedures were based primarily on tape (Wilson et al. 1977). For details of potential deleterious effects (considered minimal) of the devices used, see Wilson et al. (2002a,b, 2003) and Wilson \& Liebsch (2003). Units were fitted on all penguins for the duration of a single foraging trip, lasting between 10 and $36 \mathrm{~h}$.

\section{RESULTS}

Most of the penguin forays underwater consisted of 3 distinct phases: a descent phase, a phase when the birds swam horizontally (here termed the bottom phase), and an ascent phase (Fig. 1). During 15297 dives (minimum depth reached defined as $\geq 1 \mathrm{~m}$ ) performed by our Magellanic penguins, descent and ascent durations were related to maximum depth as follows: descent duration = 0.56 (max. depth) $+7.1\left(\mathrm{r}^{2}=0.44, \mathrm{p}<0.001\right)$ and ascent duration $=0.57$ (max. depth) $+7.7\left(\mathrm{r}^{2}=0.39, \mathrm{p}<0.001\right)$. Bottom duration accounted for a mean of $42 \%(\mathrm{SD}=21)$ of the total dive duration and was related to maximum dive depth as follows: bottom duration $=7.473(\max$. depth $)+7.7\left(r^{2}=0.22, p<0.001\right)$. Although swim speed was roughly constant throughout the dive, it increased significantly during the ascent in all individuals (Fig. 1b) with the effect being more extreme in deeper dives (Table 1). If prey capture events are excluded (Wilson et al. 2002), swim speed remained essentially constant during the bottom phase (Fig. 1b), irrespective of the depth at which this occurred (Table 1). The flipper angular velocity (the product of flipper beat frequency and amplitude, and a measure of how hard the birds were working to move (Kooyman \& Ponganis 1998, Skrovan et al. 1999) also changed systematically during the course of the dives; flipper angular velocity decreased during the course of the descent to a constant value maintained over the bottom phase, before decreasing further during the ascent (Fig. 1C). During the descent and ascent phases flipper angular velocity was dependent on maximum dive depth, being higher for any given depth during the descent in deep dives than in shallow dives (Table 1) and lower for any given depth during the ascent in deep dives than in shallow dives (Table 1). Interestingly, flipper angular velocity during the bottom phase did not change substantially with the depth (Fig. 2a).

The maximum pre-dive beak angle was positively correlated with the maximum dive reached during the dive for all birds examined ( $p<0.01$ in all cases, $n=5$ ) although there was considerable inter-individual variance both in actual angle with respect to depth, as well as the line of best fit (Fig. 2b). Independent work examining penguins diving in captivity demonstrates that diving penguins do not usually exhale underwater at any phase of the dive (Ropert-Coudert et al. 2002). 
Table 1. Spheniscus magellanicus. Summary of dive parameters from free-living Magellanic penguins. Values show means (SD) derived from 5 birds taken from regressions of speed or flipper angular velocity against depth for 3 different maximum depth categories

\begin{tabular}{|llll|}
\hline & Dives to $10 \mathrm{~m}$ & Dives to 20 m & Dives to 30 m \\
\hline Swim speed (m s ${ }^{-1}$ ) for: & & & \\
Descent phase (at 5 m depth) & $2.47(0.42)$ & $2.26(0.38)$ & $2.41(0.53)$ \\
Bottom phase (all depths) & $2.36(0.32)$ & $2.30(0.34)$ & $2.24(0.36)$ \\
Ascent phase (at 5 m depth) & $2.41(0.28)$ & $2.52(0.32)$ & $2.87(0.34)$ \\
Flipper angular velocity ( $\%$ s) for: & & & \\
Descent phase (at 5 m depth) & $707(69)$ & $774(84)$ & $852(113)$ \\
Bottom phase (all depths) & $587(65)$ & $586(64)$ & $585(65)$ \\
Ascent phase (at 5 m depth) & $484(96)$ & $214(37)$ & $19(40)$ \\
\hline
\end{tabular}

\section{DISCUSSION}

The change in flipper angular velocity over the course of the dive can be attributed to changes in buoyancy that occur as a result of changing pressure with depth (Lovvorn et al. 1991, 1999, Williams et al. 2000, Hays et al. 2004). Having inhaled a particular amount of air, and having a fixed amount of air in the plumage (Wilson et al. 1992), a descending penguin must work against the upthrust in order to descend although, at constant speed, the power associated with this will decrease with increasing depth, as the air volume will be compressed, resulting in reduced upthrust. During the return to the surface the penguin can be aided by the upthrust and thus has to work less, ultimately being able to glide over the last few metres to the surface as the increasing air volume with decreasing depth produces enough upthrust to drive the bird there passively (Sato et al. 2002, van Dam et al. 2002). Notably, the increase in Magellanic penguin swim speed approaching to surface, despite reduced flipper movement, may be a consequence of constant drag and trajectory angle but increasing air-mediated upthrust. Thus far, this situation is apparently the reverse of that exhibited by some diving pinnipeds and has been noted, for example, in both king penguins Aptenodytes patagonicus and Adélie penguins Pygoscelis adeliae. Interestingly, however, neither of these deeper-diving species increase swim speed with decreasing depth (Sato et al. 2002), perhaps due to ascent rate-reducing strategies that might help obviate the bends.

Two features make the avian situation notably different from that described for pinnipeds. Magellanic penguins exhibit substantially more locomotor effort for the descent in dives going deeper (and less in such dives during the ascent), and the locomotor effort is constant during the bottom phase of dives irrespective of the depth (Table 1). The only explanation for this is that during the bottom phase of dives, penguins have a constant upthrust, irrespective of the depth. To achieve this, they must have a constant volume at the relevant depth and thus must inhale appropriately at the surface before the dive (Sato et al. 2002). This is not the first time that pre-dive preparation at, or near, the surface has been shown to be correlated with subsequent dive performance. Wilson (2003) reported that the number of pre-dive breaths and the descent angle is also related to maximum depth in Magellanic penguins. Similarly, turtles inhale according to the resting depth of their dives (Minamikawa et al. 1997, 2000, Hayes et al. 2004). In fact, examination of the maximum beak angle occurring during the last breath before submergence in Magellanic penguins, which directly correlates with the volume of inspired air (Wilson et al. 2003), shows that it increases significantly with increasing maximum dive depth in all birds (Fig. 2b. It should be noted that the inter-individual variability here stems primarily from that between beak angle and volume of air inhaled; Wilson et al. 2003). In other words, Magellanic penguins do indeed inhale just enough air to achieve a particular, low buoyancy at the preferred depth during the bottom phase of the dive. By so doing they save energy, as they do not have to work substantially against the upthrust at this time. A comparable, though not depthrelated, strategy has been observed in trained tufted ducks Aythya fuligula, which were able to reduce underwater metabolic rate by inhaling less (Stephenson et al. 1989).

Apart from the inversion of the power phases, there is a subtle difference between the penguin energy saving locomotor solution and that displayed by marine mammals. Expiration before diving in pinnipeds, a feature thought to hinder decompression sickness (Kooyman 1989), leads not only to a passive descent phase (Williams et al. 2000) but also to a systematic downthrust for the animals during the bottom phase of dives. Presumably, energy must be expended for the animals to counteract this downthrust over the whole of the bottom phase. Magellanic penguins apparently inhale just enough for the upthrust to always be minimal (although presumably not quite neutral) for the whole of the bottom phase. By doing this, travel costs are minimized over the wide variety of depths used by these birds during their respective, extended bottom phases.

In fact, the energetic savings of this strategy obviously increase with increasing bottom duration, the effort involved in the descent tending to be cancelled 
out by the gains in the ascent. We note that dive duration in our studied penguins, as well as in birds generally, is closely related to maximum dive depth (Butler \& Jones 1997) although, apart from the fact that it will take longer to reach deeper depths, there appears no intrinsic reason for this. In particular, there is no apparent reason why penguins should not dive for extended durations to shallow depths. The answer to
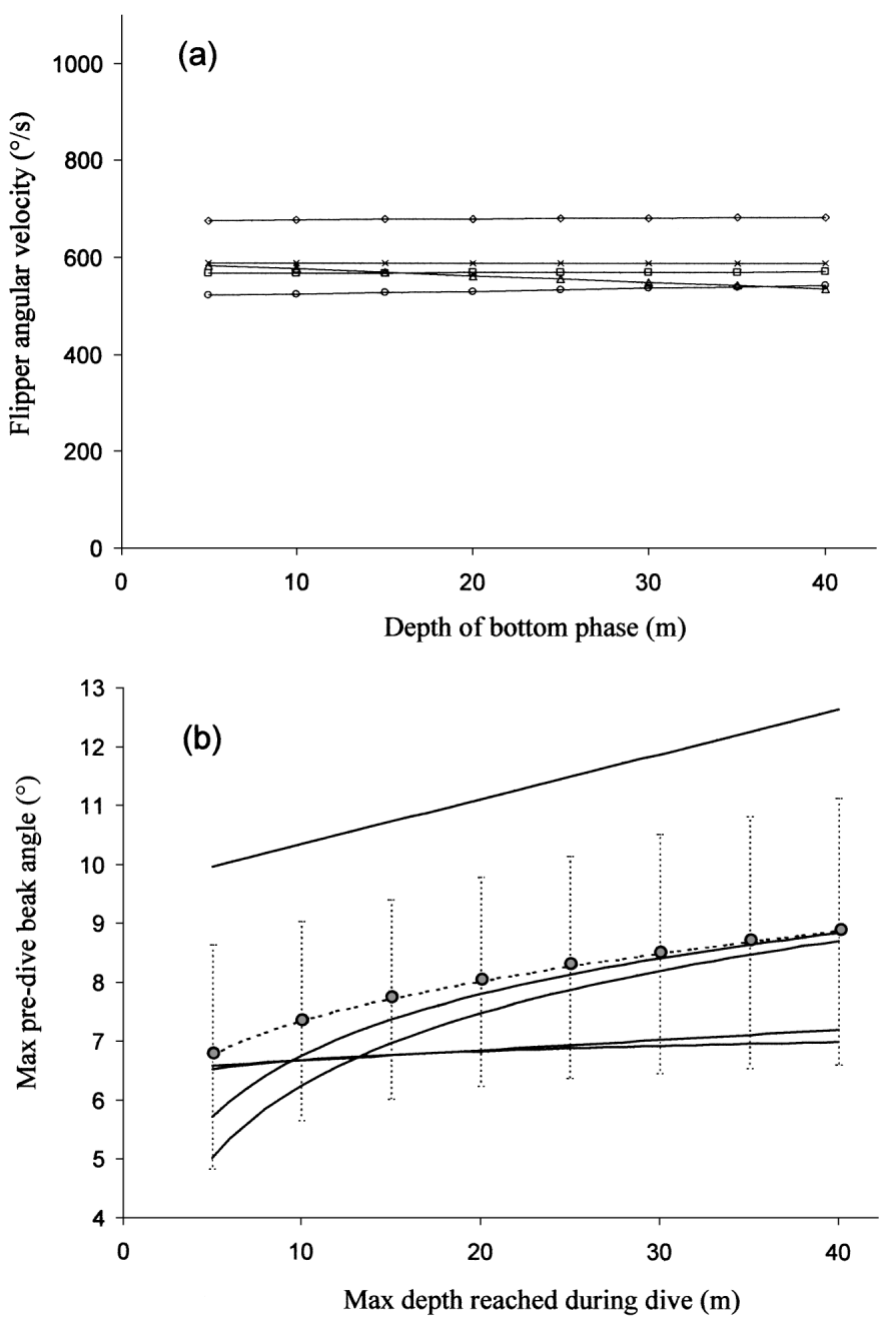

Fig. 2. Spheniscus magellanicus. (a) Flipper angular velocity (Wilson \& Liebsch 2003) during the bottom phase of dives in relation to the depth at which the bottom phase occurred. Each line is derived from a regression taken from an individual Magellanic penguin. For an estimate of the variance about the values see Table 1. (b) Relationship between maximum beak angle during the last inspiration before diving and the maximum depth reached during the dive. Maximum beak angle is linearly related to tidal volume (Wilson et al. 2003). Each line is derived from an appropriate regression $(p<0.01)$ from an individual Magellanic penguin with log or linear fits being used according to which gave the closest fit to the data. The dotted line with grey symbols shows the mean from all birds. Bars show SD this may lie in the constraints implicated in the lung volumemediated minimal buoyancy strategy shown by Magellanic penguins. Lungs and air sacs contain between about 150 and $355 \mathrm{ml} \mathrm{kg}{ }^{-1}$ and thus constitute a substantial fraction of the potential body oxygen stores (Butler \& Jones 1997); deep dives therefore allow birds to take substantial oxygen stores down with them. Such stores could not be taken down by shallow-diving birds without incurring exceptionally high energetic costs, something which would tend to reduce dive duration. To avoid such high energetic costs shallow-diving birds submerge with reduced volumes of air, but thereby reduce total body oxygen stores and are restricted to shorter dive durations. An analogous situation has been reported for turtles, where those lying on the seabed can only do so motionless, and therefore with minimum energy expenditure, if they are negatively buoyant. This means that their lung volumes must be regulated, giving them less air at shallower depths (Hays et al. 2004). However, turtles are essentially benthic and move comparatively slowly, therefore inspired air volume is not expected to vary greatly from dive to dive, whereas Magellanic penguins, with their pelagic diving behaviour (Peters et al. 1998) may change the depth of the bottom phase substantially on a dive to dive basis and must correct accordingly.

The present study and others (e.g. Williams et al. 2000) make it clear that pinnipeds and birds appear to deal with body-associated air quite differently according to the extent of that air, in order to minimize travel costs. The fundamental difference between these 2 groups would appear to be in the air volumes associated with the feathers and in the respiratory system. Our study highlights the case of the Magellanic penguin, a prolific but relatively shallow-diving bird and the equivalent case study for mammals (Williams et al. 2000) deals with a dolphin, a whale and 2 seal species, all of which dive comparatively deep and have little air associated with their body surfaces. However, intermediates occur, for example the relatively shallow-diving otariids (Schreer et al. 2001), which have an appreciable pelage presumably containing significant quantities of air (Costa \& Gales 2003), and the remarkably deep-diving Emperor penguins Aptenodytes forsterii (Schreer et al. 2001). Whether these animals have an intermediate strategy that results in energy savings, allowing them to exploit the water column effectively, remains to be seen.

Acknowledgements. This work was supported by ICSU under the auspices of SCAR. The work was approved by the Consejo Agrario de Santa Cruz, Argentina. We are particularly grateful to Silvina Sturzenbaum and Antje Steinfurth for help, logistic and otherwise. 


\section{LITERATURE CITED}

Au D, Weihs D (1980) At high speeds dolphins save energy by leaping. Nature 284:548-550

Butler PJ, Jones DR (1997) Physiology of diving of birds and mammals. Physiol Rev 77:837-899

Costa DP, Gales NJ (2003) Energetics of a benthic diver: seasonal foraging ecology of the Australian sea lion, Neophoca cinerea. Ecol Monogr 73:27-43

Crocker DE, Gales NJ, Costa DP (2001) Swimming speed and foraging strategies of New Zealand sea lions, Phoarctos hookeri. J Zool 254:267-277

Hays GC, Metcalfe JD, Walne AW (2004) The implications of lung regulated buoyancy control for dive depth and duration. Ecology 85:1137-1145

Kooyman GL (1989) Diverse divers. Springer-Verlag, Berlin

Kooyman GL, Ponganis PJ (1998) The physiological basis of diving to depth: birds and mammals. Annu Rev Physiol 60: $19-32$

Lovvorn JR, Jones DR, Blake RW (1991) Mechanics of underwater locomotion in diving ducks: drag, buoyancy and acceleration in a size gradient of species. J Exp Biol 144: 90-107

Lovvorn JR, Croll DA, Liggins GA (1999) Mechanical versus physiological determinants of swimming speeds in diving Brünnichs's guillemots. J Exp Biol 202:1741-1752

Minamikawa S, Naito Y, Uchida I (1997) Buoyancy control in diving behavior of the Loggerhead Turtle, Caretta caretta. J Ethol 15:109-118

Minamikawa S, Naito Y, Sato K, Matsuzawa Y, Bando T, Sakamoto W (2000) Maintenance of neutral buoyancy by depth selection in the loggerhead turtle Caretta caretta. J Exp Biol 203:2967-2975

Peters G, Wilson RP, Scolaro JA, Laurenti S, Upton J, Gallelli $\mathrm{H}$ (1998) The diving behavior of the Magellanic penguin (Spheniscus magellanicus) at Punta Norte, Peninsula Valdes, Argentina. Colon Waterbirds 21:1-10

Ropert-Coudert Y, Kato A, Wilson RP, Kurita M (2002) Short underwater opening of beak following immersion in 7 penguin species. Condor 104:444-448

Sato K, Naito Y, Kato A, Niizuma Y and 5 others (2002) Buoyancy and maximal diving depth in penguins: do they control inhaling air volume. J Exp Biol 205:1189-1197

Sato K, Mitani Y, Cameron MF, Siniff DB, Naito Y (2003) Factors affecting stroking patterns and body angle in diving Weddel seals under natural conditions. J Exp Biol 206:1461-1470

Schmidt-Nielsen K (1972) Locomotion: Energy cost of swimming, flying, and running. Science 177:222-228

Schreer JF, Kovacs KM, O'Hara Hines RJ (2001) Comparative diving patterns of pinnipeds and seabirds. Ecol Monogr 71:137-162

Editorial responsibility: Otto Kinne (Editor),

Oldendorf/Luhe, Germany
Skrovan RC, Williams TM, Berry PS, Moore PW, Davis RW (1999) The diving physiology of bottlenose dolphins (Tursiops truncatus). II. Biomechanics and changes in buoyancy at depth. J Exp Biol 202:2749-2761

Stephenson R, Turner DL, Butler PJ (1989) The relationship between diving activity and oxygen storage capacity in the tufted duck (Aythia fuligula). J Exp Biol 141:265-275

Thompson D, Hiby AR, Fedak MA (1993) How fast should I swim? Behavioural implications of diving physiology. Symp Zool Soc Lond 66:349-368

van Dam RP, Ponganis PJ, Ponganis KV, Levenson DH, Marshall G (2002) Stroke frequencies of emperor penguins diving under the sea ice. J Exp Biol 205:3769-3774

Williams TM (1999) The evolution of cost efficient swimming in marine mammals: limits to energy optimization. Phil Trans R Soc Lond Ser B 354:193-201

Williams TM, Friedl WA, Fong ML, Yamada RM, Sedivy $P_{\text {, }}$ Haun JE (1992) Travel at low energetic cost by swimming and wave-riding bottle-nosed dolphins. Nature 355: 821-823

Williams TM, Davis RW, Fulman LA, Francis J, Le Boeuf BJ, Horning M, Calambokidis J, Croll DA (2000) Sink or swim: Strategies for cost efficient diving by marine mammals. Science 288:133-136

Wilson RP (2003) Penguins predict performance. Mar Ecol Prog Ser 249:305-310

Wilson RP, Liebsch N (2003) Up-beat motion in swinging limbs: New insights into assessing movement of freeliving marine vertebrates. Mar Biol 142:537-547

Wilson RP, Hustler K, Ryan PG, Noeldeke C, Burger AE (1992) Diving birds in cold water: do Archimedes and Boyle determine energy costs. Am Nat 140:179-200

Wilson RP, Pütz K, Peters G, Culik B, Scolaro JA, Charrassin JB, Ropert-Coudert Y (1997) Long term attachment of transmitting and recording devices to penguins and other seabirds. Wildl Soc Bull 25:101-106

Wilson RP, Steinfurth A, Ropert-Coudert Y, Kato A, Kurita M (2002a) Lip-reading in remote subjects: an attempt to quantify and separate ingestion, breathing and vocalisation in free-living animals. Mar Biol 140:17-27

Wilson RP, Ropert-Coudert Y, Kato A (2002b) Rush and grab strategies in foraging marine endotherms: The case for haste in penguins. Anim Behav 63:85-95

Wilson RP, Simeone A, Luna-Jorquera G, Steinfurth A, Jackson S, Fahlman A (2003) Patterns of respiration in diving penguins: is the last gasp an inspired tactic? J Exp Biol 206:1751-1763

Yoda K, Sato K, Niizuma Y, Kurita M, Bost CA, Le Maho Y, Naito Y (1999) Precise monitoring of porpoising behaviour of Adélie penguins determined using acceleration data loggers. J Exp Biol 202:3121-3126

Submitted: February 12, 2004; Accepted: June 1, 2004 Proofs received from author(s): August 12, 2004 